\title{
mLearning Versus Paper and Pencil Practice for Telling Time: Impact for Attention and Accuracy
}

\author{
Cynthia F. DiCarlo ${ }^{1}$ D Aaron R. Deris $^{2} \cdot$ Thomas P. Deris $^{3}$
}

Accepted: 10 May 2021 / Published online: 9 June 2021

(C) This is a U.S. government work and not under copyright protection in the U.S.; foreign copyright protection may apply 2021

\begin{abstract}
The purpose of this study was to investigate the impact of mLearning or mobile device practice on the attention and accuracy of student's use of math concepts, specifically, telling time. A single subject, alternating treatment design was used to compare mLearning to paper and pencil practice in four 3rd grade male students. Results were mixed; two children were observed to be more on-task during the mLearning practice, and two children were observed to perform similarly across both conditions. Additionally, two children performed similarly on correctly completed problems across both conditions, and two children performed better using paper and pencil practice. All students completed more math problems during the paper and pencil practice.
\end{abstract}

Keywords IPad app $\cdot$ mLearning $\cdot$ Technology $\cdot$ Math $\cdot$ Elementary

\section{Introduction}

Seventy-five percent of homes in the USA have internet access and digital devices (Hatzigianni \& Margetts, 2014), highlighting that technology is now accessible to an increasing number of families. In spite of recommendations from the American Academy of Pediatrics (2016) to limit screen time, professional organizations are recognizing that technology can promote effective learning if used intentionally (National Association for the Education of Young Children, 2012). Increasingly, there is a recognition that the integration of technology in the classroom

Cynthia F. DiCarlo

cdicar2@1su.edu

1 School of Education, Louisiana State University, Baton Rouge, LA 70806, USA

2 Department of Special Education, Minnesota State University, Mankato, Edina, MN 55435, USA

3 Prior Lake-Savage Schools, Glendale Elementary, 6601 Connelly Parkway, Savage, MN 55378, USA 
should begin with preservice preparation (Tondeur et al., 2016). Teachers and school districts are struggling to determine the best ways to take advantage of children's interest in technological devices for enhanced learning (Larabee et al., 2014). One such technology is mLearning, which refers to the use of mobile devices to aid in student learning (Sharma \& Kitchens, 2004). As has become clear with the onset of COVID-19 and the closing of schools and the mitigating of face-to-face teaching, there is both much promise and much development needed in the mLearning arena.

Although many schools have integrated the use of mLearning (e.g., iPads) into daily practices, there is recognition that many classrooms are not using these technologies in ways that maximize their potential (Greaves et al., 2010). Skeptics have cautioned the use of the allure of using technology for the sake of technology or making the use of technology the goal (Ellison, 2015; McKenzie, 2013; Provonost, 2012). One use of technology in schools is substitution. This is taken from the Substitution Augmentation Modification Redefinition model (SAMR) which is a framework for the use of technology (Puentedura, 2012). Substitution is an introductory form of technology utilization, in which technology instruction serves as a substitute for traditional instruction. Larabee et al. (2014) found that $90 \%$ of elementary teachers reported that technology improved their children's understanding of a topic, with improvements attributed to the ability of the technology to differentiate to the needs of the learner (Milman et al., 2014). However, further research on using mLearning in K-12 settings is needed (Laskin \& Avena, 2016; National Mathematics Advisory Panel, 2008). One recommendation is that preservice elementary education teachers have required planning for technology-rich instruction (Polly \& Rock, 2016).

Typical math lessons in 2nd through 5th grade last an average of 54-61 min, consisting of a whole group lesson with worksheet practice (Banilower et al., 2013). Homework is often a mix of new concepts and previously taught concepts to review, which usually requires that one to two worksheets be completed at home. However, many elementary school parents find themselves re-teaching math concepts at home via worksheets sent for additional practice (Courture, 2012). The addition of math manipulatives has been demonstrated to help children have a greater understanding of math concepts (Courture, 2012). It seems that the interactive nature of manipulatives aids in the learning process.

In order to assess the benefits of practice to master a skill, there are several factors that must be addressed: attention, problem completion, and accuracy. Attention is the first of four requisite components in Social Learning Theory (Bandura, 1977). Teachers may capitalize on the novelty of technological devices, which may make it easier for teachers to garner child attention when addressing skills children find challenging. A variety of digital technology (e.g., iPad, iPod touch, computer, smartphone) has been demonstrated to increase engagement and children learning (Ash, 2011; Banister, 2010; Donovan et al., 2010; Franklin, 2011; Hill, 2011; Li $\&$ Pow, 2011). Specifically, this research has demonstrated that children were more engaged with iPads than direct instruction from their teacher (Bryant et al., 2015) or worksheets (Haydon et al., 2012). Correct completion of problems should be considered, as research has established that "[p]ractice facilitates the acquisition and 
maintenance of skills" (Dougherty et al., 2004, p. 18) specifically, when there is accuracy in problem completion.

The main research question guiding this study was, what are the implications of learning math concept (telling time) when using an iPad or paper and pencil worksheet. The focus of the present study was to measure children's attention when using a technological device (iPad) as compared to traditional practice (paper and pencil) when practicing math problems. Additionally, children's accuracy of math problems was also measured.

\section{Method}

\section{Participants and Setting}

The study was conducted in a public 3rd grade classroom in the Midwest serving 23 children, 13 boys and 10 girls. All children were functioning within normal limits for their age according to the Northwest Evaluation Association's Measure of Academic Progress (NWEA - MAP, 2016). At the onset of the study, children ranged in age from 8 years, 4 months to 9 years, 5 months. The four male participants included three Caucasian children, Bill, Doug, and Lucas, and one Asian child, Robert. The children in the study were targeted due to difficulty with the math concept of telling time, as evidenced by a telling time one-minute assessment (see Fig. 2). All children in the classroom were provided with the telling time one-minute assessment, and all children scoring less than $50 \%$ were invited to participate. The first four children, whose parents returned the consent form, were chosen as the participants. The targeted children each scored less than $50 \%$ accuracy on a one-minute assessment on telling time. Institutional Review Board approval was obtained, as well as parent consent and child assent. Data were collected over the course of a two-month period (March-May), prior to the start of standardized testing.

The classroom was an open-model concept classroom with children work spaces that were arranged in four L-shaped clusters consisting of 5 or 6 children desks. Children rotated between whole group instruction, small group, and independent work time throughout the day. Children received whole group instruction in one of three spaces depending on the lesson: on the carpet in front of the SMARTboard, at their desks, or in a circle in the middle of the classroom. During math, children received 20-25 min of whole group instruction before moving to ten to $15 \mathrm{~min}$ of small group activity, followed by 15-20 min of independent work time. During independent work time, children first complete selected math workbook pages for the day, then have a choice of independent activities (e.g., start math homework, math worksheet, play a math game, online math activity with either an iPad or the Chromebook). 


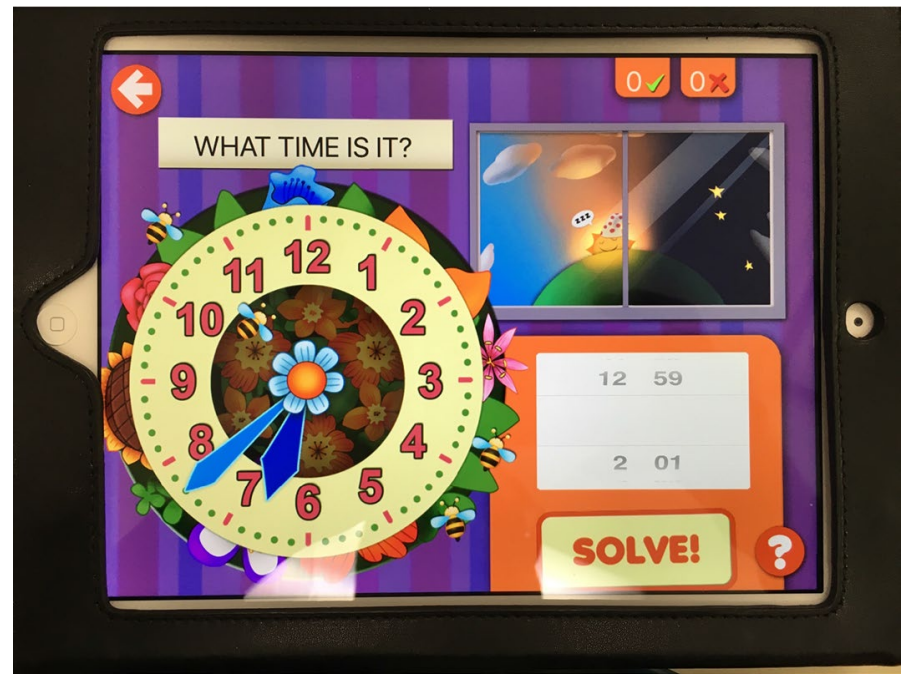

Fig. 1 Screenshot of Interactive Telling Time-Learning to tell time is fun app for iPad

\section{Experimental Design and Dependent Variables}

A single-subject multi-element design measured time-on-task and correct completion of math skills prior to and during both the Interactive Telling Time-Learning to tell time is fun app (see Fig. 1 for a screen shot of the app) for iPad and traditional paper and pencil practice interventions. A multi-element design was used to measure the impact of the Interactive Telling Time-Learning to tell time is fun app for iPad as compared to the traditional paper and pencil practice (see Fig. 2 for an example) across children. In this alternating-treatments design, the two treatments (traditional paper and pencil practices and mLearning practice) were balanced (equally distributed) across sessions.

\section{Procedures}

Observations were video recorded by the third author in the children's natural environment. Data were collected during the independent work time of the math block with familiar adults. Targeted children rotated between the two treatments of traditional paper and pencil practice and mLearning (iPad mobile device practice) for a period of $10 \mathrm{~min}$, while the teacher walked around and helped other children. Bill began at 10:20am and began paper and pencil practice rotating every day for ten days. Doug began at 10:30am and began the mLearning practice rotating every day for ten days. Lucas began at 10:40am and began paper and pencil rotating every day for ten days. Robert began at 10:50am and began the mLearning practice rotating every day for ten days. Children worked in the same work space within the classroom for all ten days. 
Name:

\section{Telling Time}

Write the time shown.

a.

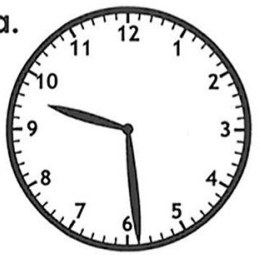

d.

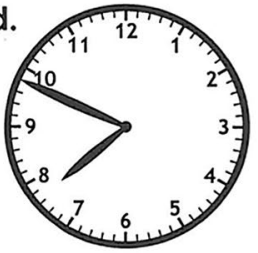

g.

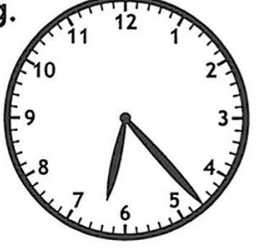

b.

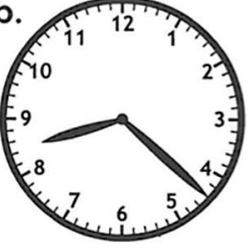

e.
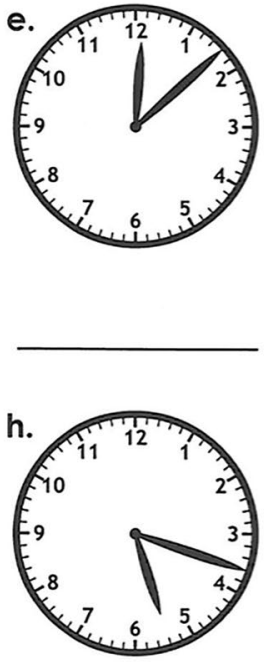

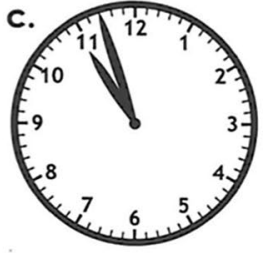

f.
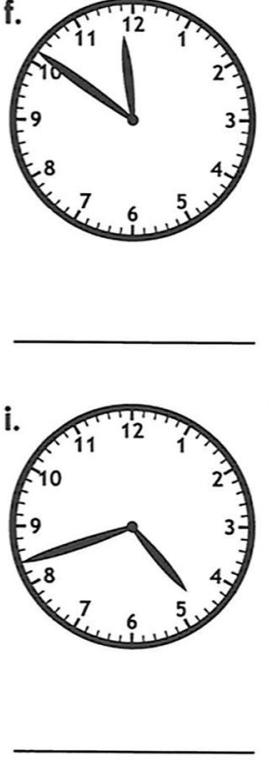

Super Teacher Worksheets - www.superteacherworksheets.com

Fig. 2 Pretest of mathematics knowledge of telling time

Both the paper and pencil worksheet and the mLearning practice focus on the same two activities related to one-minute telling time. Children worked on paper and pencil practice for ten minutes on two types of telling time worksheets. One consisted of drawing hands on a clock, and the other consisted of writing in the time depicted on the clock face. Both activities focused on one-minute telling time. Children worked on the Interactive Telling Time-Learning to tell time 
is fun app worked for ten minutes on two types of telling time activities. One activity consisted of rotating hands on a clock, and one consisted of selecting the time on the clock face. Children worked at their own pace with no interruption or assistance from the teacher. Paper and pencil practice sessions were collected and graded by the teacher, while mLearning data was collected from the Interactive Telling Time-Learning to tell time is fun app. In both conditions, only completed problems were scored. The percent correct was calculated by dividing the number of correctly completed problems by the number of total problems completed.

\section{Behavior Definitions}

\section{Child Attention}

On-Task On-task was defined as engagement with independent math practice. Looking was defined as the child looking at the task (either the paper and pencil or the mLearning). Manipulation was defined as interaction with a material using hands.

Off-Task Off-task behavior was defined as lack of engagement with independent math practice. If the child looked at things other than the math practice materials, manipulating materials other than the math practice materials, he is considered offtask. This included getting up and leaving the math practice materials to engage in any other activity. A child was considered to be off-task if he looked away or ceased manipulation for a period of $15 \mathrm{~s}$.

\section{Correct Completion}

Correct completion was defined as the percentage that the child completed correctly during a session.

\section{Interventions}

\section{mLearning Practice}

For the purposes of this study, mobile technology practice was provided via a digital application on an iPad. The Interactive Telling Time-Learning to tell time is fun app for iPad was used to provide children with independent practice on math skills. The process used to choose this application followed the recommendations outlined by Powell (2014). This app was available in iTunes for $\$ 2.99$ and was used to address the 3rd grade Minnesota state geometry and measurement standard: use of time, money, and temperature to solve real-world and mathematical problems. The app also addressed standard 3.3.3.1 benchmark: telling time to the minute, using digital and analog clocks. Settings were changed to reflect 1-min telling time practice and reflected both reading a clock and dragging the hands to the correct time. The skills included on the Interactive Telling Time-Learning to tell time is fun app are identical to the skills children are able to practice on the paper and pencil 
worksheets. Typically, upon completion of independent math practice, the teacher would have assessed whether the child needed additional practice or if the child was ready to move on to a different skill, using the criteria of $80 \%$ accuracy. The progression of skills for telling time would be, to the hour and $30 \mathrm{~min}$, next would be 5-min increments, then 1-min increments, then quarter to and quarter after, then 5-min till-, 20 min till-, and lastly would be elapsed time. The children in the study were all working on 1-min increments, and this was the sole focus of the intervention. The teacher previously prepared both paper and pencil worksheet math practice that addressed skills in the 3rd grade common core math sequence as well as identified iPad applications that addressed these same skills.

Children were provided with directions on how to use the app. A gradual release of responsibility model (Fisher \& Frey, 2008) was used. First the teacher instructed the children on how to complete problems on the worksheet and demonstrated one problem, then the teacher and the child did one problem together, and then the child did one problem without any assistance. If the child was unable to successfully complete one problem without assistance, then the teacher provided additional guidance on using the app. No additional guidance was provided and children were able to start the intervention as long as the child was able to use the app correctly, regardless of getting a correct answer or not, during the gradual release of responsibility instruction setting.

\section{Paper and Pencil Practice}

For the purpose of this study, traditional practice was defined as paper and pencil tasks that include but not limited to "multiple-choice tests, true/false tests, short answers, and essays" (Dikli, 2003, p. 13). Teacher-created worksheets were used from the website www.mathfactcafe.com to provide children with independent practice on math skills. Worksheets from this site were used as they addressed the 3rd grade Minnesota state geometry and measurement standard: use of time, money, and temperature to solve real-world and mathematical problems. The worksheets also addressed standard 3.3.3.1 benchmark. Teacher created the worksheet to reflect one-minute telling time practice and reflected both reading a clock and drawing the hands to correct time. The skills included on the Interactive Telling Time-Learning to tell time is fun app were identical to the skills children were able to practice on the paper and pencil worksheets.

Children were provided with directions on completing the paper and pencil worksheets. A gradual release of responsibility model (Fisher \& Frey, 2008) was used, first the teacher instructed the children on how to use the app and demonstrated one problem, then the teacher and the child did one problem together, and then the child did one problem without any assistance. If the child was unable to successfully complete one problem without assistance, then the teacher provided additional guidance on the worksheet. No additional guidance was provided and children were able to start the intervention as long as the child was able to complete (write an answer) on the worksheet, regardless of getting a correct answer or not, during the gradual release of responsibility instruction setting. 


\section{Data Collection}

Data was collected each day by videotaping the independent math work time for a period of ten minutes. An iPhone was placed in a tripod within a 6-foot range and was used to record the independent math time. During this time, the teacher provided the target child with either the paper \& pencil practice or the mLearning practice. Children were reminded of the amount of time (ten minutes) they had to work on the independent math work and were encouraged to work as independently as possible, without asking the teacher for assistance. A timer was set for $10 \mathrm{~min}$ and an audible alarm noted the child for when to stop working.

Interval recording was used to measure child's on-task and off-task behavior while engaged in independent math across both practice conditions. Data was recorded continuously using fifteen second intervals. Partial interval recording was used to record on-task behavior; this means that if the child exhibits on-task behavior during any part of the interval, on-task behavior was recorded. Whole interval recording was used to measure off-task behavior; this means that the child had to be off-task for the duration of the interval for off-task behavior to occur.

\section{Interobserver Reliability}

The second and third authors were the data collectors for the present study. The second author was considered the primary data collector and trained the third author using both written instructions and through feedback from scoring videotaped practice sessions to teach behavior definitions, the interval recording procedures, and the ethics of observational research, until $80 \%$ reliability was achieved. Interobserver reliability checks were conducted on $20 \%$ of all observation sessions $(n=8)$. Interobserver reliability was calculated on an interval-by-interval basis measured the number of times the research assistant and primary researcher agreed or disagreed. The formula used to calculate interobserver agreement was to divide the number of agreements by the total number of agreements plus disagreements and multiply by 100 . For reliability purposes, the tenminute sessions were divided into 40 fifteen-second intervals. Inter-observer agreement for occurrences of on-task and off-task behavior was 97.5\% (range: 80-100\%).

\section{Social Acceptability}

A measure of child social acceptability was conducted to determine child opinion on preference of iPad or pencil and paper worksheets when completing math practice. The student questionnaire included four objective questions and five open-ended questions. Questions asked students to state a preference between the iPad and the worksheet to determine preference when practicing telling time, enjoyment, focus, and which medium they felt more confident in getting correct answers. Additionally, children were asked in an open-ended format what they like best and least about the iPad, and what they liked best and least about the worksheets. Children were also invited to provide any additional comments on the study. 


\section{Results}

\section{On-Task Behavior}

Comparisons across the mLearning practice and paper and pencil practice conditions were mixed (Fig. 3); two children were observed to be more on-task during the mLearning practice, and two children were observed to perform similarly across both conditions. Comparably, when Bill had access to the mLearning, he was observed to be on task $100 \%$ (range, 100-100\%) of the observed intervals, as compared to the paper and pencil practice where he was observed to be on task 85\% (range, 77-95\%). For Bill, there was a 15-percentage point increase in on-task behavior when the mLearning practice was implemented. Similarly, when Doug had access to the mLearning he was observed to be on task 100\% (range, 100-100\%) of the observed intervals, as compared to the paper and pencil practice where he was observed to be on task $96 \%$ (range, $90-100 \%$ ). There was a $4 \%$ point increase in on-task behavior when the mLearning condition was implemented. When Lucas had access to the mLearning, he was observed to be on task 94\% (range, 82-100\%) of the observed intervals, as compared to the paper and pencil practice where he was observed to be on task $86 \%$ (range, 77-95\%). There was an 8-percentage point increase in on-task behavior when the paper and pencil condition was implemented. When Robert had access to the mLearning, he was observed to be on task $95 \%$ (range, $80-100 \%$ ) of the observed intervals, as compared to the paper and pencil practice where he was observed to be on task 77\% (range, 37-100\%). There was an 18-percentage point increase in on-task behavior when the mLearning condition was implemented.

\section{Percentage of Correctly Completed Problems}

Comparisons of accuracy across the mLearning practice and the paper and pencil practice conditions were mixed (Fig. 4); two children were observed to correctly complete more math problems using the paper and pencil practice and two children were observed to perform similarly across both conditions.

Bill completed more problems correctly during paper and pencil practice. When Bill had access to the mLearning, he correctly completed math problems $66 \%$ (range, $42-90 \%$ ) of the observed intervals, as compared to the paper and pencil practice where he correctly completed math problems $74 \%$ (range, 68-78) of the observed intervals. There was an 8-percentage point increase in correctly completed math problems when the traditional paper and pencil practice condition was implemented. Doug performed similarly across both conditions on correctly completed math problem. When Doug had access to mLearning, he correctly completed math problems 90\% (range, $87-93 \%$ ) of the observed intervals, as compared to the paper and pencil practice where he correctly completed math problems $83 \%$ (range, 72-90\%) of the observed intervals. There was a seven-percentage point increase in correctly completed math problems when the mLearning condition was implemented. Lucas 


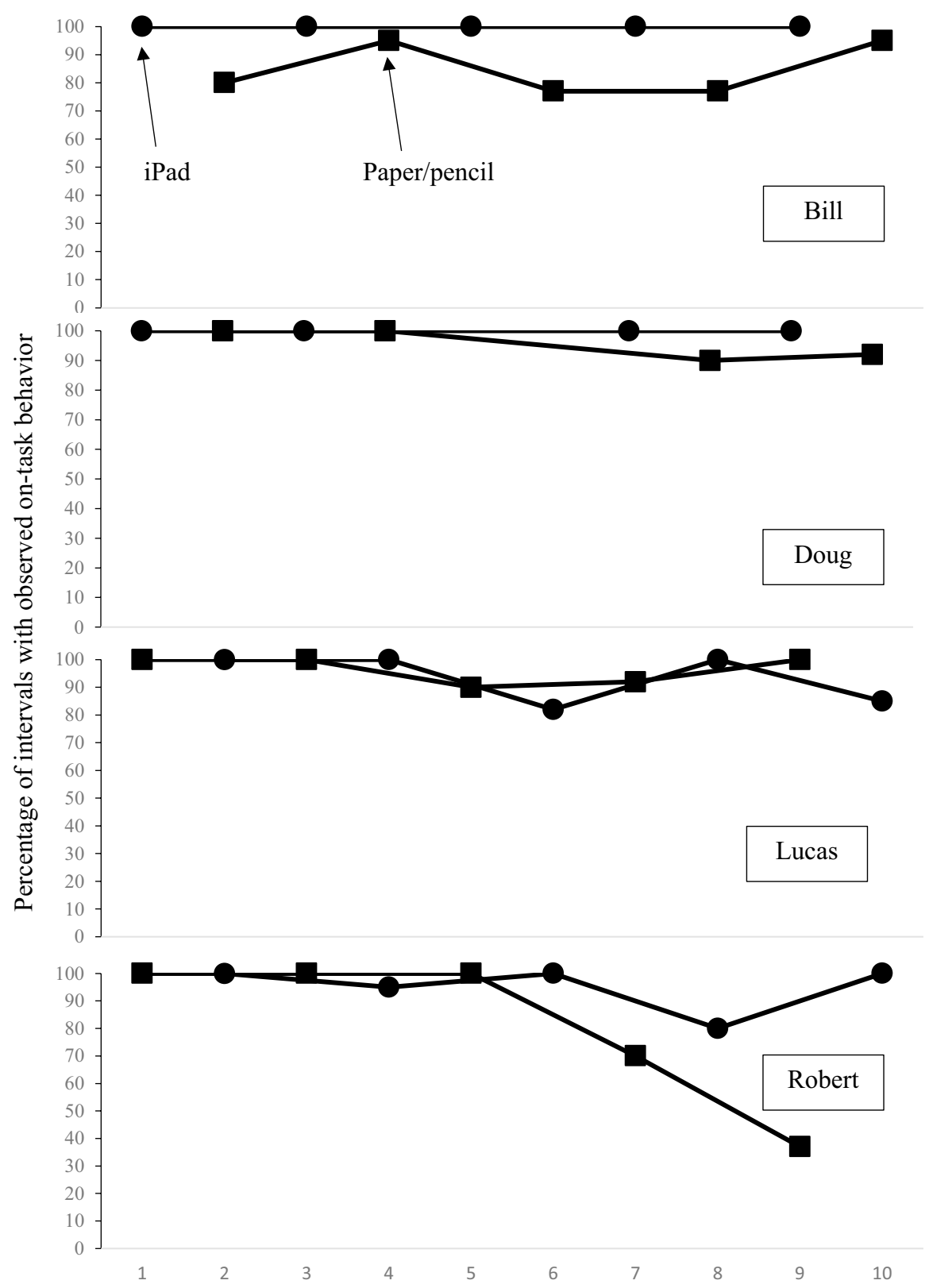

Fig. 3 Percentage of observed intervals with on-task behavior across mobile device and paper and pencil practice of math skills 


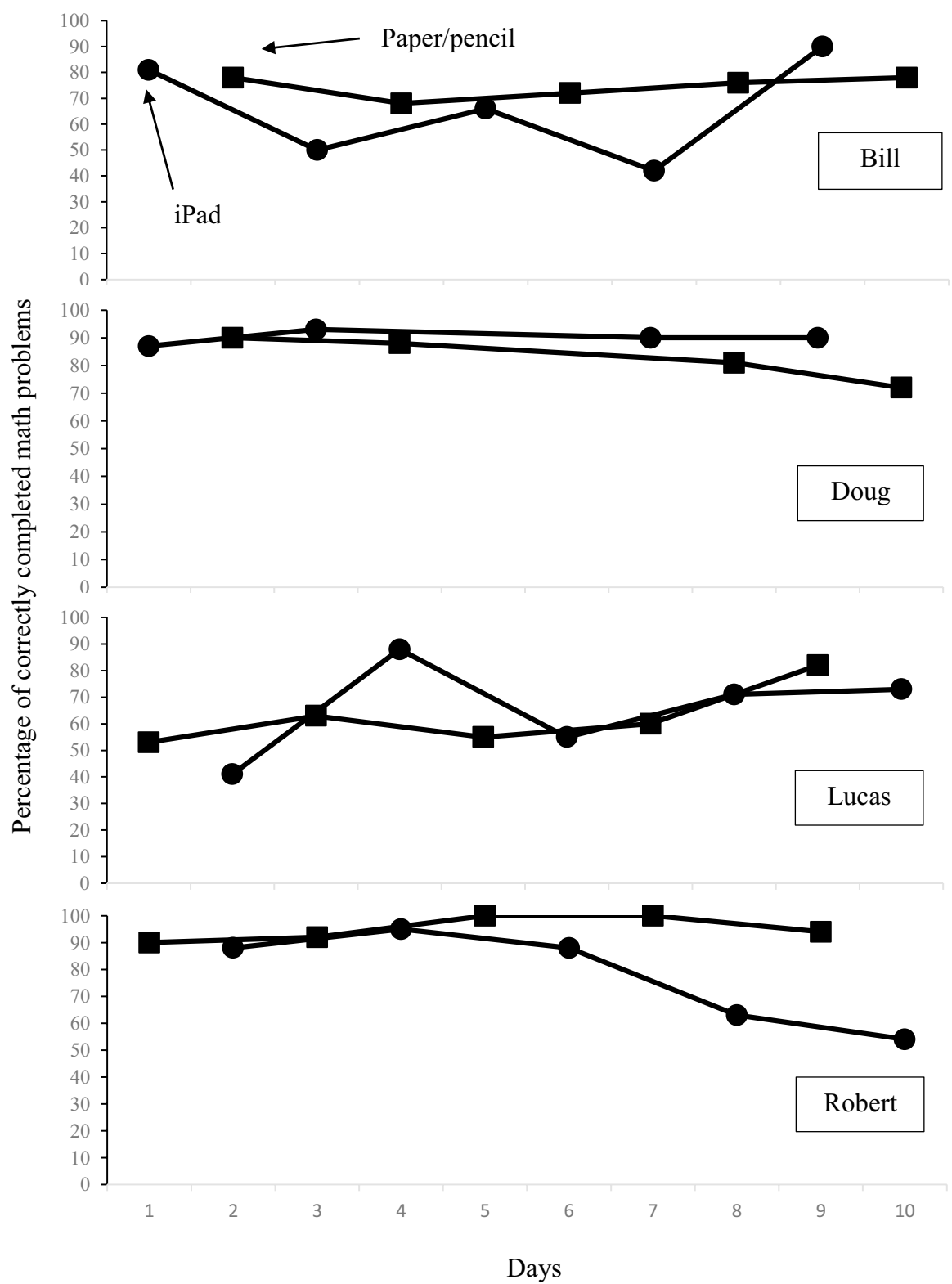

Fig. 4 Percentage of correctly completed math problems across mobile device practice and the paper \& pencil practice of math skills

performed similarly across both conditions on correctly completed math problem. When Lucas had access to the mLearning, he correctly completed math problems 66\% (range, 41-88\%) of the observed intervals, as compared to the paper and pencil practice where he correctly completed math problems 63\% (range, 53-82\%) 
of the observed intervals. There was a two-percentage point increase in correctly completed math problems when the mLearning practice was implemented. Robert completed more problems correctly during paper and pencil practice. When Robert had access to the mLearning, he correctly completed math problems $78 \%$ (range, $54-95 \%$ ) of the observed intervals, as compared to the paper and pencil practice where he correctly completed math problems 95\% (range, 90-100\%) of the observed intervals. There was an 18-percentage point increase in correctly completed math problems when the traditional condition was implemented.

\section{Number of Completed Math Problems}

Comparisons between the mLearning practice and the paper and pencil practice showed that children completed more math problems during the paper and pencil condition as compared to the mLearning condition (Fig. 5). On average, children completed 25 problems (range, $21-33$ problems) when using the paper and pencil practices compared to the children completing on average eleven math problems (range, 7-17 problems) when the mLearning condition was implemented. This represents an increase of fourteen math problems completed, on average, when children used the traditional practice, rather than the mLearning practice. Bill averaged 23 problems (range, 20-32) completed during the paper and pencil practice and 8 problems (range, 3-18) during the mLearning practice. Doug averaged 33 problems (range, 21-45) completed during the paper and pencil practice and 17 problems (range, 14-20) during the mLearning practice. Lucas averaged 21 problems (range, 15-34) completed during the paper and pencil practice and 7 problems (range, 5-12) during the mLearning practice. Robert averaged 24 problems (range, 17-32) completed during the paper and pencil practice and 13 problems (range, 10-15) during the mLearning practice.

\section{Social Acceptability}

Results of the social acceptability measure were mixed. Although the majority of children reported that they enjoyed the iPad more than the worksheets, all four children stated that they preferred the worksheets when practicing telling time math skills. Three of four children felt that they got more answers correct and could focus more when using worksheets. However, three of four children reported enjoying the iPad activity more than the worksheet, due to the touch screen and because it was "like a game." Children reported that they did not like to scroll up and down when using the iPad, that the problems were "hard" and that if you missed a problem, you did not get a point. Although the problems on the worksheets were identical to those on the iPad, two students reported that the worksheet problems were easier, and another liked being able to write in the answer, rather than select it on the touch screen. However, when asked what they did not like about the worksheets, children reported that there were "too many pages." 


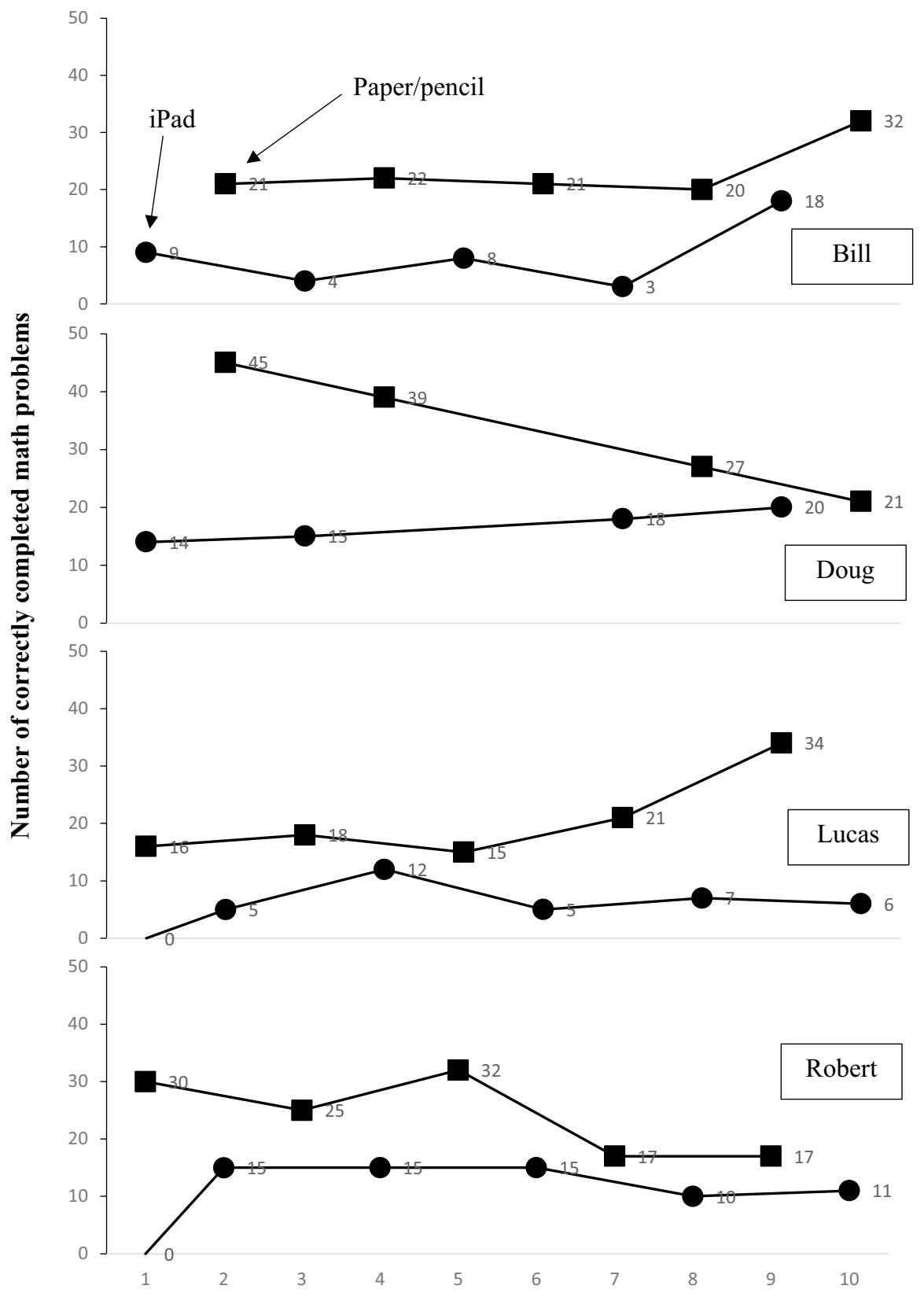

Days

Fig. 5 Number of correctly completed math problems across the mobile device and the paper and pencil practice of math skills 


\section{Discussion}

This study sought to determine if there was a difference between the use of iPad or paper and pencil on attention and accuracy. Findings from the present study echo several studies found in the recent literature using iPad technology. Past research regarding mathematics interventions with technology have been focused on task on behavior (Flower, 2014; Riley et al., 2014) and correctly completed math problems (Haydon et al., 2012).

\section{Attention}

The majority of the children in this current study (three) were observed to be more on-task during the mLearning practice, which is similar to the finding that children were more engaged with iPads in the Haydon et al. (2012) study. Other researchers have also found that technology usage was effective in holding children's attention (Parkhurst et al., 2010). The increase in attention to task is not surprising as this has been noted as a benefit of technology in past research (Musti-Rao et al., 2015; Thoermer \& Williams, 2012).

\section{Accuracy}

Kiger et al. (2012) found that children in 3rd grade who had an intervention using an iPod Touch scored higher than children that used traditional means for an intervention to learn multiplication. However, the current study showed that children who used mLearning had a lower percentage of correct answers compared to paper and pencil. Musti-Rao and Plati (2015) found that while children increased their knowledge using both traditional and iPad interventions, children using the iPad performed better. Similarly, the current research showed that children who used mLearnings had a higher percentage of correct answers compared to paper and pencil. In another study by Haydon et al. (2012), an alternating treatment design was used to compare iPads to worksheets, finding that children had higher level of correct problems using an iPad than using worksheets. Again, this current research showed that children who used mLearnings had a higher percentage of correct answers compared to paper and pencil.

\section{Implications of the Results}

The current study adds to the body of literature supporting the use of technology interventions in elementary schools (Burns et al., 2012; Ysseldyke et al., 2005). Educators can use the results of this study to help determine which practice, either paper and pencil or mLearning fit their children' needs more effectively. Children using mLearning practice were observed to be more on task compared to paper and pencil practice. However, children completed more math problems correctly using paper and pencil practice. Therefore, mLearning practice may be more effective in daily math practice, whereas paper and pencil may be more 
effective when time is limited or when a formative paper and pencil assessment is needed. Educators should look for interactive mLearning apps that provide math skills that complement daily math instruction, then allow children independent practice time daily on the app throughout the unit prior to prior to a summative paper and pencil assessment. Children who struggle with specific skills may need more time on the mLearning or may require access to multiple mLearning apps targeted at the same math skill. A pretest of each math unit will likely determine which children need more time and practice on the mLearning app in order to be successful on the unit test.

Findings from Ransom and Manning (2013) indicated that teachers using paper and pencil practices do not pause to reflect on their true effectiveness. Findings from Greaves et al. (2010) found that schools that are using technologies such as mobile devices are not using these tools effectively in the classroom settings. Results of the present study demonstrate that mLearnings can be used effectively in the classroom especially for math. More importantly, the specific app largely dictates the success or failure of using mLearnings in the classroom as well as the amount of time the teacher gives to researching the right app, guided practice with children and allowing enough time to observe children using the device. Using technology in the classroom requires educators to understand the various apps used and how they correlate with daily lessons as well as the connection between paper and pencil assessments and mLearning practices.

Results offer support for the need for guidance in the use of technology in the schools, rather than the use of technology for the sake of technology. One promising model is the Substitution Augmentation Modification Redefinition model (SAMR; Puentedura, 2012), which challenges educators to look at the functional use of technology in learning. In the present study, iPads were used to substitute practice on telling time. Romrell et al. (2014) advocate that any technology should promote independent learning, personalization, student voice, critical thinking, and creativity.

\section{Social Acceptability}

While children seemed to enjoy the novelty of the iPad app, overall, they stated a preference for the worksheets. This may be in part because of their history of learning through paper and pencil tasks. Being able to see problems seemed to have advantages for some children who stated that they felt they got more answers correct on the worksheet, however, one student complained at the number of pages in the worksheet packet. When using an iPad, children cannot determine the number of problems they got correct so far or the number of problems remaining to complete. Depending on the child, this could be viewed as a positive or a negative. As technological devices become more widely accepted as legitimate learning tools in the classroom, children may become more comfortable in their use of these tools. Johnson (2012) stated that children often convince themselves they are either good or bad as a result of the score on their worksheet. Children may feel more freedom to engage using a mobile device, as there is no grade attached. 


\section{Limitations of the Study}

One limitation of this study may have been that the study was conducted at the end of the year (4th quarter) when focusing on school work may be additionally challenging for children. Additionally, the study ceased when the standardized testing for the school began, as teachers focused on testing. Children had to work for $10 \mathrm{~min}$ blocks, one after the next for a total of 40-min while their peers worked independently for 40-min on other math activities. Off-task behavior was recorded on a whole interval basis, which may have underestimated the amount of time children spent off task.

As children were exposed to technology on a regular basis with frequent access to both iPads and Chromebooks in the classroom, often daily, this could be considered a limitation. mLearning was not novel and was part of their normal learning environment. Perhaps, if children who were not exposed to technology in the classroom regularly then they may have performed differently.

Another limitation of this study is all four children knew they were being videotaped and perhaps were more on task due to the fact that they knew they were being recorded and eventually the data would be used in a study. The iPhone that recorded each video was placed about four-feet away, but remained in view. Perhaps, if the recording device was on the opposite side of the classroom the children may have been less aware and may have changed their behavior.

Additionally, the mLearning app, Interactive Telling Time-Learning to tell time is fun app, required time to load each problem. If the app was quicker, children may have completed more problems. The mLearning math app took between 12 and $15 \mathrm{~s}$ for the digital clocks to stop spinning for each problem. Children then took between ten to fifteen seconds to select the hour hand using a scrolling-number dial and ten to fifteen seconds to select the minute hand using a different number dial. Then, children had to hit submit and wait for the screen to tell them if they were correct and to reload which took another five seconds. Therefore, each problem took between 37 and $50 \mathrm{~s}$. In a given ten-minute block of time, children were unlikely to complete more than ten to fifteen problems unless they were very fast at selecting the hour and minute hand correctly the first time. While the third author implemented standard procedures for both the iPad app and paper and pencil practice regarding the completion of problems, no fidelity data were collected on these procedures.

Finally, this study examined the use of one mobile application-Interactive Telling Time-Learning to tell time is fun-and compared its use to paper and pencil practice. Our findings are limited in that we focused on one application.

\section{Future Research}

Suggestions for future research would include replicating the current study with variety of genders, and math subject content. All of the participants were male, it is unknown if there might be differences in regard to female students and their responses to the intervention. The subject content of telling time is one of the most 
difficult tasks for children to learn (Burny et al., 2012). A different third-grade standard may have different results. More research should be conducted on how mLearnings such as iPad and Chromebooks are used to teach and reinforce learning in young children. An interesting comparison would be to compare iPads to Chromebooks or other technology to determine if one is more advantageous for children growth. Future research should use partial interval recording in measuring children's off task behavior; the use of whole interval recording may have underestimated offtask behavior. As this research was conducted in the natural environment, the study ceased as children began standardized testing. All instruction and time were focused on preparing for the standardized testing. Future research is needed to determine if greater differences might be found in a study of a longer duration.

\section{Practical Implications}

In summary, the current study adds to the literature base regarding technology and traditional classroom models. The results of the study provide continued evidence for students being more engaged with using an iPad than with paper and pencil. Implications for classroom teachers would be that the use of an iPad does have students more engaged with work for practice of skills. The results of this study add to the need for more research on the mLearnings in K-12 settings (Milman et al., 2014; Tamim et al., 2011) and will hopefully motivate administrators to understand the need to support teachers in the use of technology.

Funding Funding was not received for this study.

\section{Declarations}

Ethical Approval All procedures performed in studies involving human participants were in accordance with the ethical standards of the institutional and/or national research committee and with the 1964 Declaration of Helsinki and its later amendments or comparable ethical standards.

\section{References}

American Academy of Pediatrics (2016). Media and children communication toolkit. Retrieved from https://www.aap.org/en-us/advocacy-and-policy/aap-health-initiatives/pages/media-and-children. aspx

Ash, K. (2011). California district pushes digital: Text initiative forward. Education Week Digital Directions. Retrieved from http://www.edweek.org/dd/articles/2011/02/09/02books.h04.html

Bandura, A. (1977). Social learning theory. General Learning Press.

Banilower, E. R., Smith, P. S., Weiss, I. R., Malzahn, K. A., Campbell, K. M., \& Weis, A. M. (2013). Report of the 2012 national survey of science and mathematics education. Horizon Research Inc.

Banister, S. (2010). Integrating the iPod touch in K-12 Education: Visions and vices. Computers in the Schools, 27(2), 121-131. https://doi.org/10.1080/07380561003801590

Bryant, B. R., Kim, M. K., Ok, M. W., Kang, E. Y., Bryant, D. P., Lang, R., \& Son, S. H. (2015). A comparison of the effects of reading interventions on engagement and performance for fourth-grade students with learning disabilities. Behavior Modification, 39(1), 167-190. https://doi.org/10.1177/ 0145445514561316 
Burns, M. K., Kanive, R., \& DeGrande, M. (2012). Effect of a computer-delivered math fact intervention as a supplemental intervention for math in third and fourth graders. Remedial and Special Education, 33, 184-191.

Burny, E., Valcke, M., Desoete, A., \& Hans Van Luit, J. (2013). Curriculum sequencing and the acquisition of clock-reading skills among Chinese and Flemish children. International Journal of Science and Mathematics Education, 11, 761-785.

Chiong, C., \& Shuler, C. 2010. Learning: Is there an app for that? Investigations of young children's usage and learning with mobile devices and apps. The Joan Ganz Cooney Center at Sesame Workshop. Retrieved from http://pbskids.org/read/les/cooney_learning_apps.pdf

Courture, K. (2012). Math manipulatives in increase 4th grade student achievement. Math Manipulatives, $3,1-44$.

Dikli, S. (2003). Assessment at a distance: Traditional versus alternative assessments. Turkish Online Journal of Educational Technology, 2(3), 13-19.

Donovan, L., Green, T., \& Hartley, K. (2010). An examination of one-to-one computing in the middle school: Does increased access bring about increased student engagement? Journal of Educational Computing Research, 42(4), 423-441. https://doi.org/10.2190/EC.42.4.d

Dougherty, S. S., Chase, P. N., \& O'Shields, E. M. (2004). Effects of rate building on fluent performance: A review and commentary. The Behavior Analyst, 27, 7-23.

Ellison, D. (2015). At what point does it become technology for technology's sake? Retrieved from https://tech.co/technology-for-technologys-sake-2015-10

Fisher, D., \& Frey, N. (2008). Better learning through structured teaching: A framework for the gradual release of responsibility. ASCD.

Flower, A. (2014). The effect of iPad use during independent practice for students with challenging behavior. Journal of Behavioral Education, 23(4), 435-448. https://doi.org/10.1007/s10864-014-9206-8

Franklin, T. (2011). Mobile learning: At the tipping point. Turkish Online Journal of Educational Technology, 10(4), 261-275.

Greaves, T., Hayes, J., Wilson, L., Gielniak, M., \& Peterson, R. (2010). The technology factor: Nine keys to student achievement and cost-effectiveness. MDR. Retrieved from https://www.k12blueprint.com/ sites/default/files/Project-RED-Technolgy-Factor.pdf

Hatzigianni, M., \& Margetts, K. (2014). Parents' beliefs and evaluations of young children's computer use. Australasian Journal of Early Childhood, 39(4), 114-122.

Haydon, T., Hawkins, R., Denune, H., Kimener, L., McCoy, D., \& Basham, J. (2012). A comparison of iPads and worksheets on math skills of high school students with emotional disturbance. Behavioral Disorders, 37(4), 232-243.

Hill, R. A. (2011). Mobile digital devices. Teacher Librarian, 59(1), 22-26.

Johnson, D. (2012). Stretching your technology dollar. Educational Leadership, 12, 30-33.

Kiger, D., Herro, D., \& Prunty, D. (2012). Examining the influence of a mobile learning intervention on third grade math achievement. Journal of Research on Technology in Education, 45(1), 61-82.

Kratochwill, T. R., Hitchcock, J., Horner, R. H., Levin, J. R., Odom, S. L., Rindskopf, D. M. \&Shadish, W. R. (2010). Single-case designs technical documentation. Retrieved from What Works Clearinghouse website: http://ies.ed.gov/ncee/wwc/pdf/wwc_scd.pdf

Larabee, K., Burns, M., \& McComas, J. (2014). Effects of an iPad-supported phonics intervention on decoding performance and time on-task. Journal of Behavioral Education, 23, 449-469. https://doi. org/10.1007/s10864-014-9214-8

Laskin, A., \& Avena, J. (2016). Introduction of mobile media into formal classroom learning environments. Journal of Mass Communication Educator, 70(3), 276-285.

Li, S. C., \& Pow, J. C. (2011). Affordance of deep infusion of one-to-one tablet-PCs into and beyond classroom. International Journal of Instructional Media, 38(4), 319-326.

McKenzie, J. (2013). Technology for the sake of technology: False promise, false prophets and false notions. From now on: The Educational Technology Journal, 22(3). Retrieved from http://fno.org/ Jan2013/techsake.html

Milman, N. B., Carlson-Bancroft, A., \& Vanden Boogart, A. (2014). Examining differentiation and utilization of iPads across content areas in an independent, prek- $4^{\text {th }}$ grade elementary school. Computers in the Schools, 31(3), 119-133.

Musti-Rao, S., Lo, Y., \& Plati, E. (2015). Using an iPad® app to improve sight-word reading fluency for at-risk first-grade children. Remedial and Special Education, 36(3), 154-166. https://doi.org/10. $1177 / 0741932514541485$ 
Musti-Rao, S., \& Plati, E. (2015). Comparing two classwide interventions: Implications of using technology for increasing multiplication fact fluency. Journal of Behavioral Education, 24(4), 9-11. https:// doi.org/10.1007/s10864-015-9228-X

National Association for the Education of Young Children and the Fred Rogers Center for Early Learning and Children's Media at Saint Vincent. (2012). Technology and interactive media as tools in early childhood programs serving children birth through age 8. National Association for the Education of Young Children; Latrobe, PA: Fred Rogers Center for Early Learning and Children's Media at Saint Vincent College.

National Mathematics Advisory Panel. (2008). Foundations for success: The final report of the national mathematics advisory panel. Department of.

Northwest Evaluation Association. (2016). Linking the Kentucky K-PREP assessments to NWEA MAP tests. Northwest Evaluation Association. Retrieved from https://www.nwea.org/about/

Parkhurst, J., Skinner, C. H., Yaw, J., Poncy, B., Adcock, W., \& Luna, E. (2010). Using technology to identify idiosyncratic math facts for additional automaticity drills. International Journal of Behavioral Consultation and Therapy, 6(2), 111-123.

Polly, D., \& Rock, T. (2016). Elementary education teacher candidates' integration of technology in the design of interdisciplinary units. TechTrends, 60(4), 336-343.

Powell, S. (2014). Choosing iPad apps with a purpose: Aligning skills and standards. TEACHING Exceptional Children, 47(1), 20-26.

Provonost, R. (2012). Technology for technology's sake. TeachingAhead: A Roundtable. Retrieved from http://blogs.edweek.org/teachers/teaching_ahead/2012/02/technology_for_technologys_sake.html

Puentedura, R. R. (2012). The SAMR model: Background and exemplars. Retrieved from http://www. hippasus.com/rrpweblog/archives/2012/08/23/SAMR_BackgroundExemplars.pdf

Ransom, M., \& Manning, M. (2013). Worksheets, worksheets, worksheet. Childhood Education, 6, $188-190$.

Riley, N., Lubans, D. R., Holmes, K., \& Morgan, P. (2014). Rational and study protocol for the EASY Minds (encouraging activity to stimulate young minds) program: Cluster randomized controlled trial of a primary school-based physical activity integration program for mathematics. BMC Public Health. https://doi.org/10.1186/147-2458-14-816

Romrell, D., Kidder, L. C., \& Wood, E. (2014). The SAMR model as a framework for evaluation mLearning. Online Learning. https://doi.org/10.24059/olj.v18i2.435

Sharma, S. K., \& Kitchens, F. L. (2004). Web services architecture for M-Learning. Electronic Journal on e-Learning, 2(1), 203-216.

Tamim, R. M., Bernard, R. M., Borokhovski, E., Abrami, P. C., \& Schmid, R. F. (2011). What forty years of research says about the impact of technology on learning: A second-order meta-analysis and validation study. Review of Educational Research, 81, 4-28.

Thoermer, A., \& Williams, L. (2012). Using digital texts to promote fluent reading. The Reading Teacher, $65,441-445$.

Tondeur, J., Roblin, N. P., van Braak, J., Voogt, J., \& Prestridge, S. (2016). Preparing beginning teachers for technology integration in education: Ready for take-off? Technology, Pedagogy and Education. https://doi.org/10.1080/14759939x.2016.1193556

Ulman, J. D., \& Sulzer-Azaroff, B. (1975). Multielement baseline design in educational research. In E. Ramp \& G. Semb (Eds.), Behavior analysis: Areas of research and application (pp. 377-391). Prentice-Hall.

Ysseldyke, J., Thrill, T., Pohl, J., \& Bolt, D. (2005). Using math facts in a flash to enhance computational fluency. Journal of Evidence-Based Practices for Schools, 6, 59-89.

Publisher's Note Springer Nature remains neutral with regard to jurisdictional claims in published maps and institutional affiliations. 